\title{
EFFECT OF DEXMEDETOMIDINE ON HAEMODYNAMICS DURING EXTUBATION IN PATIENTS UNDERGOING MASTOID TYMPANOPLASTY PROCEDURE THROUGH PROSPECTIVE OBSERVATIONAL STUDY
}

\author{
Vijaya Gaware1, Biju Sekhar², Rekha S3, Geetha George 4 \\ 1 Junior Consultant, Department of Anaesthesiology, Meitra Hospital, Edakkad, Kerala, India. \\ 2Senior Consultant, Department of Anaesthesiology, Aster MIMS Hospital, Calicut, Kerala, India. \\ 3 Senior Consultant, Department of Anaesthesiology, Meitra Hospital, Edakkad, Kerala, India. \\ ${ }^{4}$ Senior Consultant and HOD, Department of Anaesthesiology, Meitra Hospital, Kerala, India.
}

\section{ABSTRACT}

\section{BACKGROUND}

Dexmedetomidine an $\alpha 2$ agonist has been successfully used for attenuating the stress response to laryngoscopy. It is known to produce sedation, anxiolysis, hypnosis, analgesia, and sympatholysis. Thus it can reduce the requirement of inhalational agents and narcotics when used as an adjunct to general anaesthesia thereby providing smooth extubation since patient will be awake pain free and without respiratory compromise. Our objective is to study the effect of Dexmedetomidine on haemodynamics during extubation in patients undergoing mastoid-tympanoplasty procedure compared to control group through prospective observational study.

\section{MATERIALS AND METHODS}

After obtaining Institutional Ethics Committee approval, 60 ASA I -II patients undergoing Mastoid -Tympanoplasty procedure were randomly enrolled into the study. After intubation and before surgical incision, Dexmedetomidine infusion was started at the rate of $0.4 \mathrm{mcg} / \mathrm{kg} / \mathrm{hr}$., which was continued until after extubation. Intra-op monitoring consisted of ECG, non-invasive blood pressure, oxygen saturation, ETCO2; from pre-induction to post- extubation for 15 minutes. Post-op monitoring consisted of ECG, respiratory rate, NIBP, sedation score, any side effects to Dexmedetomidine. Requirement of any beta-blocker/ionotropic agents/ vasoconstrictors or vasodilators/ total IV fluids given was recorded. Postoperatively patient was followed up for 2-3 hrs for any adverse effect of study drug/postoperative complications/haemodynamic stability. Same method of anaesthetic management and monitoring was followed in patients not receiving Dexmedetomidine and peri extubation response was watched for. Data was collected and analysed using standard statistical principles.

\section{RESULTS}

Haemodynamic stability was more with Dexmedetomidine group during peri-extubation period as compared to pre-op values than control group. Both surgeon and patient satisfaction and comfort were better with Dexmedetomidine than control group because of bloodless field under microscope during surgery and sedative anxiolytic analgesic properties of Dexmedetomidine postoperatively respectively.

\section{CONCLUSION}

Dexmedetomidine at the dose studied is safe with hypotensive effect and is an alternative to traditional beta blockers for surgical procedures. Infusion of Dexmedetomidine without a loading dose appears to be adequate in maintaining haemodynamic stability without any extra sedation effect.

\section{KEY WORDS}

Dexmedetomidine, Haemodynamics, Mastoid-Tympanoplasty.

HOW TO CITE THIS ARTICLE: Gaware V, Sekhar B, Rekha S, et al. Effect of dexmedetomidine on haemodynamics during extubation in patients undergoing mastoid tympanoplasty procedure through prospective observational study. J. Evolution Med. Dent. Sci. 2018;7(51):5456-5459, DOI: 10.14260/jemds/2018/1207

\section{BACKGROUND}

Extubation produces significant haemodynamic changes comparable to laryngoscopy and tracheal intubation which can be detrimental in patients especially those with CAD.(1-7)

Dexmedetomidine an $\alpha 2$ agonist has been successfully used for attenuating the stress response to laryngoscopy. It is known to produce sedation anxiolysis hypnosis analgesia and sympatholysis.(6-13) Thus it can reduce the requirement of

'Financial or Other Competing Interest': None.

Submission 21-06-2018, Peer Review 01-12-2018,

Acceptance 08-12-2018, Published 17-12-2018.

Corresponding Author:

Dr. Vijaya Gaware,

Rachana House, Chalakkara,

New Mahe-673311, Kerala, India.

E-mail: vigal6@gmail.com

DOI: $10.14260 / j e m d s / 2018 / 1207$ inhalational agents and narcotics when used as an adjunct to general anaesthesia thereby providing smooth extubation since patient will be awake pain free and without respiratory compromise.(14-18) $\alpha-2$ adrenergic agonists in addition to its sedative effects, alpha- 2 receptor stimulation in the central nervous system inhibits sympathetic activity(14-19) and reduces plasma epinephrine and norepinephrine levels.(20-24) Dexmedetomidine has been reported useful in attenuating haemodynamic stress secondary to hyperadrenergic overreactivity and agitation associated with delirium.(25-26) Because alpha-2 receptor stimulation does not cause respiratory depression.(27-28) sedation with dexmedetomidine may facilitate the transition to unassisted breathing in agitated patients.

Dexmedetomidine a more specific and selective $\alpha-2$ adrenergic agonist and has a shorter duration of action. ${ }^{29-30)}$ 
The majority of patients receiving dexmedetomidine were effectively sedated yet were easily arousable a unique feature not observed with other sedatives. Effective analgesic-sparing sedation with minimal haemodynamic change has been reported without a loading dose prior to dexmedetomidine infusion and with low dose-infusion rates.(31)

\section{MATERIALS AND METHODS}

After obtaining Institutional Ethics Committee approval 60 patients were enrolled randomly into the study. The periextubation haemodynamic response was observed for those who were getting Inj. Dexmedetomidine and those who were not getting it through prospective observational study.

\section{Entry Criteria}

- Patients undergoing mastoid- tympanoplasty under General anaesthesia

\section{- $\quad$ ASA I - II}

\section{Exit Criteria}

In this study exclusion criteria are set because hypertensive patients can be on alpha methyl-dopa drug and in such situations study drug is not recommended to use effect of study drug on patients with BMI > 35 may be unpredictable also as extubation response is observed in the study, patients requiring post op ventilation are excluded from study.

After intubation and before surgical incision inj. Dexmedetomidine infusion was started at $0.4 \mathrm{mcg} / \mathrm{kg} / \mathrm{hr}$, which was continued until after extubation the anaesthesiologist managing the patient, who is not involved in the subsequent data collection administered the infusions.

Intra -op monitoring consisted of ECG non-invasive blood pressure, oxygen saturation, ETCO2; and the readings before induction at the time of induction post intubation, and thereafter every $30 \mathrm{~min}$ interval upto the time of giving reversal, and since then every 5 min interval, at the time of extubation and post extubation for 15 minutes were noted. Post- op monitoring consisted of ECG respiratory rate NIBP sedation score any side effects to Dexmedetomidine like bradycardia hypotension hypertension PONV allergic reaction. Also, the requirement of any betablocker/ionotropic agents/vasoconstrictors or vasodilators and total IV fluids given was recorded. Patient was reversed with Inj. Neostigmine $0.05 \mathrm{mg} / \mathrm{kg}$ and Inj. Glycopyrrolate 0.01 $\mathrm{mg} / \mathrm{kg}$ at the end of surgery.

Postoperatively patient was followed up for 2-3 hrs for any adverse effect of study drug/postoperative complication/haemodynamic stability Same method of anaesthetic management and monitoring was followed in patients not receiving Inj. Dexmedetomidine and periextubation response was watched for.

\section{Statistical Analysis}

The data was collected and analysed using standard statistical chi - square test Student's t test $\mathrm{P}<0.05-$ statistically significant. Data was entered in Microsoft excel and analysis was done using SPSS version 20.

\section{RESULTS}

The groups were comparable with respect to age ( $\mathrm{p}$ value 0.404 ), and sex ( $p$ value - 0.432 ) as distribution amongst two groups were statistically not significant. There was a higher distribution of ASA II patients in group C (Control) which was statistically not significant ( $p$ value- 0.468 ).

As Mastoid -Tympanoplasty requires intra -op induced hypotension for which Inj. Metoprolol or Inj. Labetalol were being used commonly and results were observed. The group $\mathrm{C}$ (control) received more dosage of Betablockers as compared to group D (Dexmedetomidine) where only one patient received it and the comparison was statistically significant ( $p$ value- 0.028). As per observed results use of vasoconstrictors was more in group $\mathrm{D}$ as compared to group $\mathrm{C}$ and it was statistically significant ( $\mathrm{p}$ value-0.032). Also, one patient was excluded from study because of severe hypotension and study drug was discontinued.

\section{Heart Rate}

Periextubation haemodynamic changes were compared to pre-op vitals. Observations states that heart rate variability were similar in both groups during extubation but post extubation stability was more in group D as compared to group C.

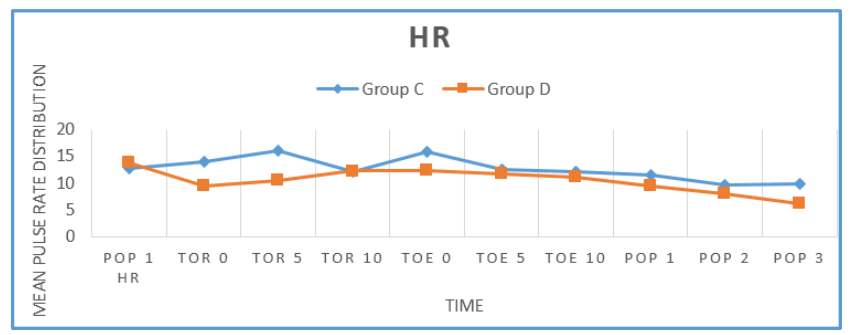

POP 1-Pre-Operative, TOR-Time of Reversal at 0, 5, 10 min., TOE- Time of Extubation at 0, 5, 10 min., POP-Post Operative at 1, 2, 3 hrs., HR-Heart Rate

\section{Systolic Blood Pressure}

As per the observations systolic BP was more stable in group $\mathrm{D}$ as compared to group $\mathrm{C}$ in periextubation period. PreOperative values were not statistically significant ( $p$ value- 1 )

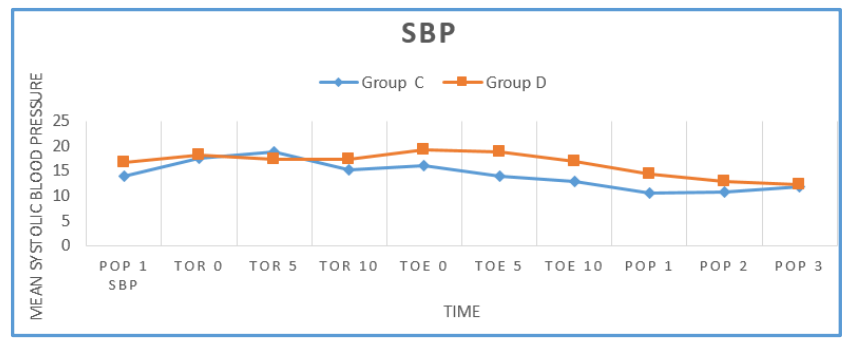

POP 1-Pre-Operative, TOR- Time of Reversal at 0, 5, 10 min., TOE-Time of Extubation at 0, 5, $10 \mathrm{~min}$, POP-PostOperative at 1, 2, 3 hrs., SBP-Systolic Blood Pressure

\section{Diastolic Blood Pressure}

Also, diastolic BP was more stable in group D. 


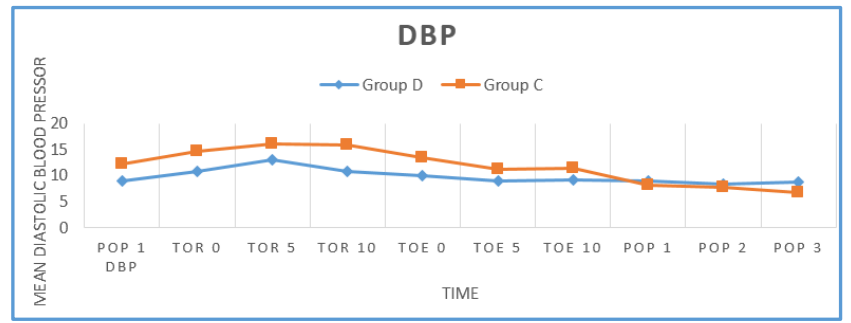

POP 1-Pre-Operative, TOR-Time of Reversal at 0, 5, 10 min., TOE- Time of Extubation at 0, 5, 10 min., POP-Post Operative at 1, 2, 3 hrs. DBP-Diastolic Blood Pressure

\section{Respiratory Rate}

Respiratory rate variability was more in group $\mathrm{C}$ as compared to group D after giving reversal agent but postextubation changes were nearly similar in both groups.

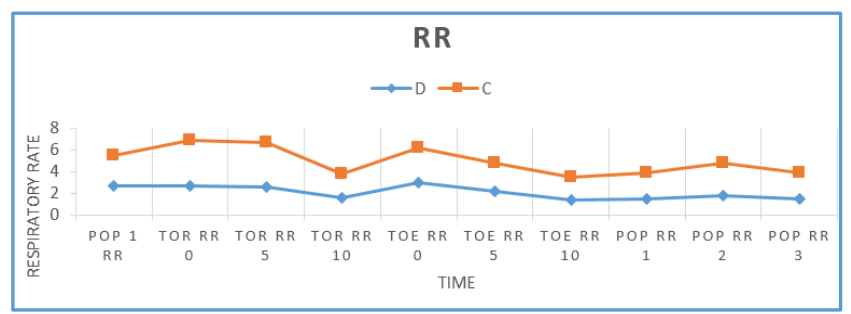

POP 1-Pre-Operative TOR-Time of Reversal at 0, 5, 10 min., TOE- Time of Extubation at 0, 5, 10 min., POP-Post Operative at 1, 2, 3 hrs. RR-Respiratory Rate

\section{Sedation Score}

0 - Awake and alert.

1 - Mildly sedated easily arousable.

2 - Moderately sedated aroused by shaking.

3 - Deeply sedated difficult to be aroused by physical stimulation.

The extent of sedation was assessed at the end of anaesthesia after extubation using post-operative sedation score (Pop SS) for 2 - 3 hrs. As per the observations group D patients showed higher sedation score (1) than group $C(0)$, but it was not statistically significant ( $p$ value- 0.455 ).

\section{Side Effects}

Both groups were observed for any untoward side effect in post -op recovery unit for $3 \mathrm{hrs}$. As per study protocol.

There was no incidence of any side effect except 3 patients in group $\mathrm{D}$ and 1 in group $\mathrm{C}$ who complained of nausea/vomiting which was treated with Inj Metoclopramide/Inj. Ondansetron, but the difference was not statistically significant.

\section{DISCUSSION}

Our study was different from other similar studies with respect to two aspects. First, we did not use a loading dose but rather began with the infusion rate of $0.4 \mathrm{mcg} / \mathrm{kg} / \mathrm{hr}$. This was done to assess whether a loading dose is necessary in the presence of other sedative agents during general anaesthesia and to avoid potential hypertension, reflex bradycardia and hypotension which is sometimes encountered during loading-dose administration secondly our study was done in patients undergoing mastoidtympanoplasty surgery where induced hypotension was beneficial during surgery to give bloodless field under microscope. To our knowledge use of dexmedetomidine to facilitate induced hypotension in this subgroup of patients has not been previously reported.

Current practice usually entails reducing or discontinuing sedation prior to extubation thus leads to agitation undesirable sympathetic stimulation use of dexmedetomidine was associated with more stable haemodynamic and respiration during entire process of extubation. There was no observed respiratory depression in both the groups.

In our study we observed 60 patients in which 1 patient was excluded from study due to development of severe hypotension for dexmedetomidine and discontinuation of it retrospectively we found out that patient received antihypertensive on the morning of the surgery. Though there were more patients in group D who had hypotension compared to group $\mathrm{C}$ they responded well to single dose of vasoconstrictor. Effects were transient and not clinically significant.

Sedation score was 1 in group $D$ as compared to 0 in group C but was not clinically significant. There were no side effects except post-operative nausea vomiting in 3 patients of Dexmedetomidine and 1 from control group. Use of antiemetics was more in Dexmedetomidine group than control in our study but the results were not statistically significant no other side effects were observed in both the groups.

Both surgeon and patient's satisfaction and comfort were better with dexmedetomidine than control group. Because of bloodless field under microscope during surgery and sedative anxiolytic properties of dexmedetomidine postoperatively respectively.

\section{CONCLUSION}

Dexmedetomidine at a dose of $0.4 \mathrm{mcg} / \mathrm{kg} / \mathrm{hr}$ provides a comfortable field for tympanoplasty surgery and stable haemodynamics during extubation without causing any respiratory depression or excessive sedation. But instead of stiff dose infusion, titrated infusion doses may be more beneficial for greater haemodynamic stability and requirement of vasoconstrictors can also be minimised.

\section{REFERENCES}

[1] Takeshima K, Nada K, Higaki M. Cariovascular response to rapid anaesthesia induction and endotracheal intubation. Anesth Analg 1964;43(2):201-8.

[2] Khan RM, Khan TZ, Hag G, et al. Tracheal extubation under intravenous xylocaine. Ind J Med Res 1990;92:189-91.

[3] Karmarkar S, Varshney S. Tracheal extubation. Continuing Education in Anaesthesia Critical Care \& Pain 2008;8(6):214-20.

[4] Fleisher LA. Perioperative myocardial ischemia and infarction. Int Anaesthesiol Clin 1994;4:1-15.

[5] Gill NP, Wright B, Reilly CS. Relationship between hypoxemia and cardiac ischemic events in the perioperative period. Br J Anaesth 1992;68(5):471-3. 
[6] Fujii Y, Saitoh Y, Takahashis S. Combined diltiazem and lidocaine reduces cardiovascular responses to tracheal extubation and anesthesia emergence in hypertensive patients. Can J Anesth 1999;46(10):952-6.

[7] Mikawa K, Nishina K, Takao Y, et al. Attenuation of cardiovascular responses to tracheal extubation: comparison of verapamil lidocaine and verapamillidocaine combination. Anesth Analg 1997;85(5):1005-10.

[8] Scheinin B, Lindgren L, Randell $\mathrm{T}$, et al. Dexmedetomidine attenuates sympathoadrenal responses to tracheal intubation reduces the need for thiopentone and perioerative fentanyl. Br J Anaesth 1992;68(2):126-31.

[9] Laurito CE, Banghman VL, Becker GL, et al. The effectiveness of oral clonidine as sedative/anxiolytic and as a drug to blunt haemodynamic responses to laryngoscopy. J Clinical Anesth 1991;3(3):186-93.

[10] Savola MK, Maclaver MB, Doze VA, et al. The alpha 2 adrenoceptor agonist dexmedetomidine increases apparent potency of volatile anesthetic isoflurane in rats in vivo and in hippocampal slice in vitro. Brain Res 1991;548(1-2):23-8.

[11] Aantaa AR, Kanto J, Scheinin $M$, et al. dexmedetomidine an alpha 2 adrenoceptor agonist reduces anesthetic requirement for patients undergoing gynaecologic surgery. Anesthesiology 1990;73(2):230-5.

[12] Scheinin $H$, Virtanen $R$, MacDonald $E$, et al. Medetomidine-a novel a-2-adrenoceptor agonist: a review of its pharmacological effects. Prog NeuroPsychopharmacol Biol Psychiatry 1989;13(5):635-51.

[13] Gertler R, Brown CH, Mitchell DH, et al. Dexmedetomidine: a novel sedative-analgesic agent. Proceedings (Bayl Univ Med Cent) 2001;14(1):13-21. www.baylorhealth.com 14

[14] Maze M, Tranquilli W. a-2 adrenoceptor agonists: defining the role in clinical anesthesia. Anesthesiology 1991;74(3):581-605.

[15] Bloor BC, Flacke WE. Reduction of halothane anesthetic requirements by clonidine an Alpha-2 drenergic agonist. Anest Analg 1982;61:741-5.

[16] Kulkarni A, Price G, Saxena M, et al. Difficult extubation: calming the sympathetic storm. Anaesth Intensive Care 2004;32(3):413-6.

[17] Flacke JW, Bloor BC, Flacke WE, et al. Reduced narcotic requirement by clonidine with improved haemodynamic and adrenergic stability in patients undergoing coronary bypass surgery. Anesthesiology 1987;67(1):11-9.

[18] Kaukinen S, Pyykko K. Potentiation of halothane anaesthesia by clonidine. Acta Anaesthesiol Scand 1979;23(1):107-11.
[19] Aantaa R, Scheinin M. a-2-adrenergic agents in anesthesia. Acta Anaesthesiol Scand 1993;37(5):4338.

[20] Quintin L, Bonnet F, Macquin I, et al. Aortic surgery: effect of clonidine on intraoperative catecholaminergic and circulatory stability. Acta Anaesthesiol Scand 1990;34(2):132-7.

[21] Housmans PR. Effects of dexmedetomidine on contractility relaxation and intracellular calcium transients of isolated ventricular myocardium. Anesthesiology 1990;73(5):919-22.

[22] Wijeysundera DN, Naik JS, Beattie WS. Alpha-2 adrenergic agonists to prevent perioperative cardiovascular complications: a meta-analysis. Am J Med 2003;114(9):742-52.

[23] Bidwai AV, Bidwai VA, Rogers CR, et al. Blood-pressure and pulse-rate responses to endotracheal extubation with and without prior injection of lidocaine. Anesthesiology 1979;51(2):171-3.

[24] Hsu YW, Cortinez LI, Robertson KM, et al. Dexmedetomidine phramacodynamics: part I: crossover comparison of the respiratory effects of dexmedetomidine and remifentanil in healthy volunteers. Anesthesiology 2004;101(5):1066-76.

[25] Herr DL Sum-Ping ST, England M. ICU sedation after coronary artery bypass graft surgery: dexmedetomidine-based versus propofol-based sedation regimens. J Cardiothorac Vasc Anesth 2003;17(5):576-84.

[26] Venn RM, Grounds RM. Comparison between dexmedetomidine and propofol for sedation in the intensive care unit: patient and clinical perceptions. $\mathrm{Br}$ J Anaesth 2001;87(5):684-90.

[27] Guler G, Akin A, Tosun Z, et al. Single dose dexmedetomidine attenuates airway and circulatory reflexes during extubation. Acta Anaesthesiol Scand 2005;49(8):1088-91.

[28] Arain SR, Ebert TJ. The efficacy, side effects and recovery characteristics of dexmedetomidine versus propofol when used for intraoperative sedation. Anesth Analg 2002;95(2):461-6.

[29] Elbaradie S, El Mahalawy FH, Solyman AH. Dexmedetomidine vs. propofol for short-term sedation of postoperative mechanically ventilated patients. J Egypt Natl Canc Inst 2004;16(3):153-8.

[30] Barletta JF, Miedema SL, Wiseman D, et al. Impact of dexmedetomidine on analgesic requirements in patients after cardiac surgery in a fast-track recovery room setting. Pharmacotherapy 2009;29(12):1427-32.

[31] Ickeringill $M$, Shehabi $\mathrm{Y}$, Adamson $\mathrm{H}$, et al. Dexmedetomidine infusion without loading dose in surgical patients requiring mechanical ventilation: haemodynamic effects and efficacy. Anaesth Intensive Care 2004;32(6):741-5. 